\title{
Erratum to: Precis of The Contents of Visual Experience
}

\section{Susanna Siegel}

Published online: 29 September 2012

(C) Springer Science+Business Media Dordrecht 2012

\section{Erratum to: Philos Stud \\ DOI 10.1007/s11098-012-0014-5}

The original version of this article contains a grammatical error. In the article's title, "Precise" should be "Precis." 